Check for updates

Cite this: RSC Adv., 2018, 8, 18084

\title{
A hybrid electric field assisted vacuum membrane distillation method to mitigate membrane fouling
}

\begin{abstract}
Qinglin Huang, (D) *abc Huan Liu, ${ }^{\text {ab }}$ Yafeng Wang ${ }^{\mathrm{b}}$ and Changfa Xiao ${ }^{\mathrm{ac}}$
We proposed a novel method for vacuum membrane distillation (VMD) called Electric Field Assisted Vacuum Membrane Distillation (EVMD) that can be used to mitigate membrane fouling. A biaxial stretching polytetrafluoroethylene (PTFE) membrane was utilized as the base membrane, and multiwalled carbon nanotubes (MWCNTs) or a mixture of MWCNTs/graphene as a conductive substrate. During EVMD, the conductive PTFE membrane acted as the cathode while a stainless-steel wire mesh surrounding the conductive membrane acted as the anode. The effect of the per unit area loading mass (PUALM) of the conductive substrate on the membrane performance were investigated. Results revealed that for a PUALM of $10 \mathrm{~g} \mathrm{~m}^{-2}$, the PTFE membrane not only exhibited excellent conductivity but also showed a high rate of gas flux. Doping graphene into the MWCNT conductive substrate led to the formation of nano-channels which served to improve the membrane distillation flux and the membrane hydrophobicity. The effects of the electric field strength as well as humic acid (HA) concentration on the antifouling performance during EVMD were also investigated. Results showed that during EVMD, the PTFE conductive membrane exhibited the best antifouling ability using an intermittent electric field with a field strength of $1.0 \mathrm{~V} \mathrm{~cm}^{-1}$.
\end{abstract}

Received 16th March 2018

Accepted 5th May 2018

DOI: $10.1039 / \mathrm{c} 8 \mathrm{ra0} 02304 \mathrm{~b}$

rsc.li/rsc-advances
However, despite its many attractive advantages, MD has yet to be widely applied. ${ }^{\mathbf{1 0}}$ The large scale development of membrane separation technologies, such as UF, NF, and MD, ${ }^{4,5,10-19}$ have been hindered by membrane fouling, a problem which results in a sharp decline in the membrane flux and shortens the membrane's lifespan. Membrane fouling during MD is primarily caused by inorganic scaling, particulate and colloidal fouling, and/ or bio-fouling. ${ }^{14}$ Natural organic matter (NOM), such as humic acid (HA), bovine serum albumin (BSA), and Sodium Alginate (SA), has also been seen to lead to membrane fouling. ${ }^{20} \mathrm{HA}$ in particular has been identified as a principal NOM foulant for membrane processes, leading many researches to focus on HA fouling during MD. ${ }^{4,11,13,21,22}$ Multiple strategies have been employed in order to inhibit membrane fouling for MD, including pretreatment of the feeding solution, membrane flushing, gas bubbling, ${ }^{18}$ surface modification to create an anti-fouling membrane, ${ }^{23}$ photo-catalysis ${ }^{24}$ and so on. ${ }^{12,25}$ Despite all efforts however, membrane fouling continues to be a challenge for implementation of the technique. ${ }^{26}$

In recent decades, electro-chemical techniques have been coupled with membrane separation technologies and applied to water treatment of industrial wastewater, ${ }^{27}$ particularly in the degradation of phenol. ${ }^{28,29}$ Many studies have shown that use of a Membrane Bioreactor (MBR) coupled with an electric field is able to effectively mitigate membrane fouling. ${ }^{.0-32}$ For example, Raed Hashaikeh used periodic electrolysis to effectively clean membranes, ${ }^{33}$ Boor Singh Lalia employed electrically conductive membranes able to self-clean any bio-fouling, ${ }^{34}$ and Li et al. ${ }^{35}$ introduced an electro-catalytic membrane reactor able to mitigate
${ }^{a}$ State Key Laboratory of Separation Membranes and Membrane Process, Tianjin Polytechnic University, 399 West Binshui Road, Xiqing District, Tianjin, 300387, P. R. China. E-mail: huangqinglin@tjpu.edu.cn; Tel: +86-22-83955795

${ }^{b}$ Department of Material Science and Engineering, Tianjin Polytechnic University, Tianjin 300387, P. R. China

${ }^{c}$ National Center for International Research on Membrane Science and Technology Tianjin Polytechnic University, Tianjin, 300387, P. R. China 


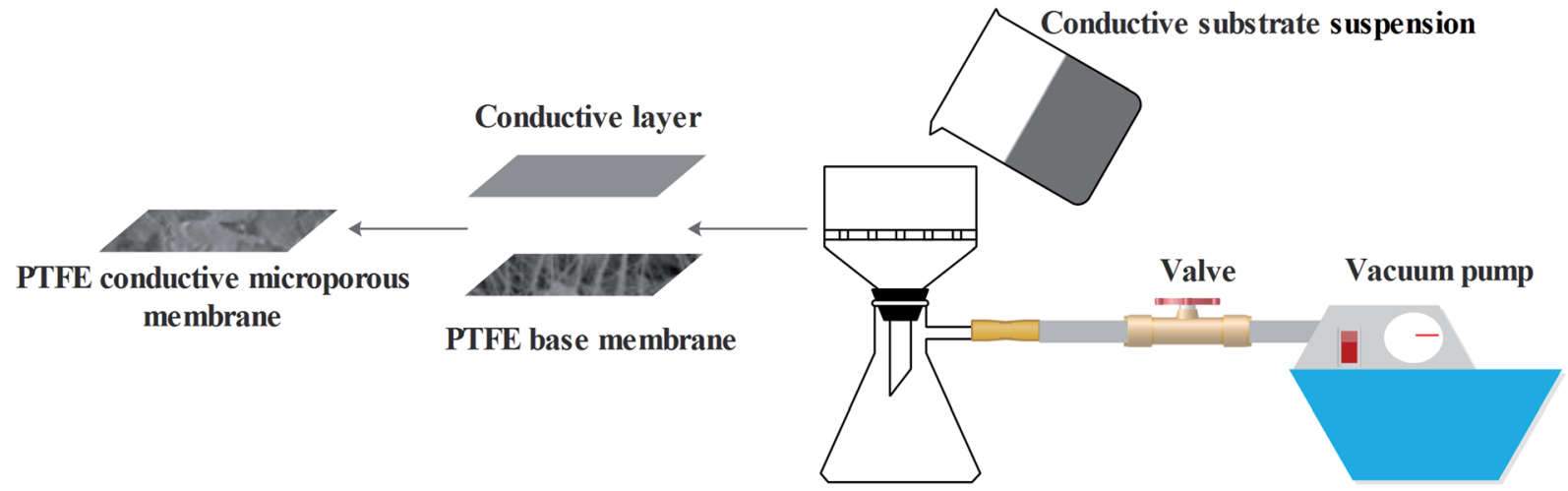

Fig. 1 Preparation of a PTFE conductive microporous membrane.

membrane fouling. More recently, carbon nanotubes and graphene have been used as good conductive materials across many fields. ${ }^{36-41}$ Use of these materials for water treatment is also developing rapidly. ${ }^{42-45}$

In this article, we propose a novel method of improved, antifouling MD called Electric Field Assisted Vacuum Membrane Distillation (EVMD). This method utilizes a biaxial stretching PTFE membrane as a base membrane and multi-walled carbon nanotubes (MWCNTs), or a mixture of MWCNTs/garphenes, as a conductive substrate. ${ }^{33,46,47}$ The effects of the per unit area loading mass (PUALM) of the MWCNTs on the overall membrane performance were investigated in terms of the surface morphology, gas flux, and conductivity. The effects of the electric field strength and HA concentration on the antifouling performance during EVMD were also investigated.

\section{Experimental}

\subsection{Materials}

Biaxial stretching PTFE membranes with an average pore diameter of $0.22 \mu \mathrm{m}$ were supplied by Haining Nengda Filter
Equipment Co., Ltd (Haining, China). Sodium chloride ( $\mathrm{NaCl}$, AR grade) was obtained from Tianjin Fengchuan Chemical Reagent Co., Ltd (Tianjin, China). Humic acid (HA, CP) was purchased from Tianjin Guangfu Fine Chemical Research Institute (Tianjin, China). Carboxylated MWCNTs were purchased from Beijing BOYU GAOKE New Material Technology Co., Ltd (Beijin, China). Graphene was obtained from Ximen Knano Graphene Technology Co., LTD (Xiamen, China). $N, N$ Dimethylacetamide (DMAc, AR grade) was obtained from Tianjin Kemiou Chemical Reagent Co., Ltd (Tianjin, China).

\subsection{Preparation of a conductive PTFE membrane}

$0.01 \%$ by wt of MWCNTs, or $0.01 \%$ by wt of a mixture of MWCNTs/ graphenes, was dispersed in DMAc using an ultrasonic cleaner with the fixing frequency set at $40 \mathrm{kHz}$ for $4 \mathrm{~h}$. Before vacuum filtration, the PTFE was soaked in ethanol in order to clean the membrane surface as well as decrease resistance during the vacuum filtration process. Next, an appropriate amount of the suspension containing the conductive substrate was filtered through the membrane using vacuum filtration at $30 \mathrm{kPa}$, as

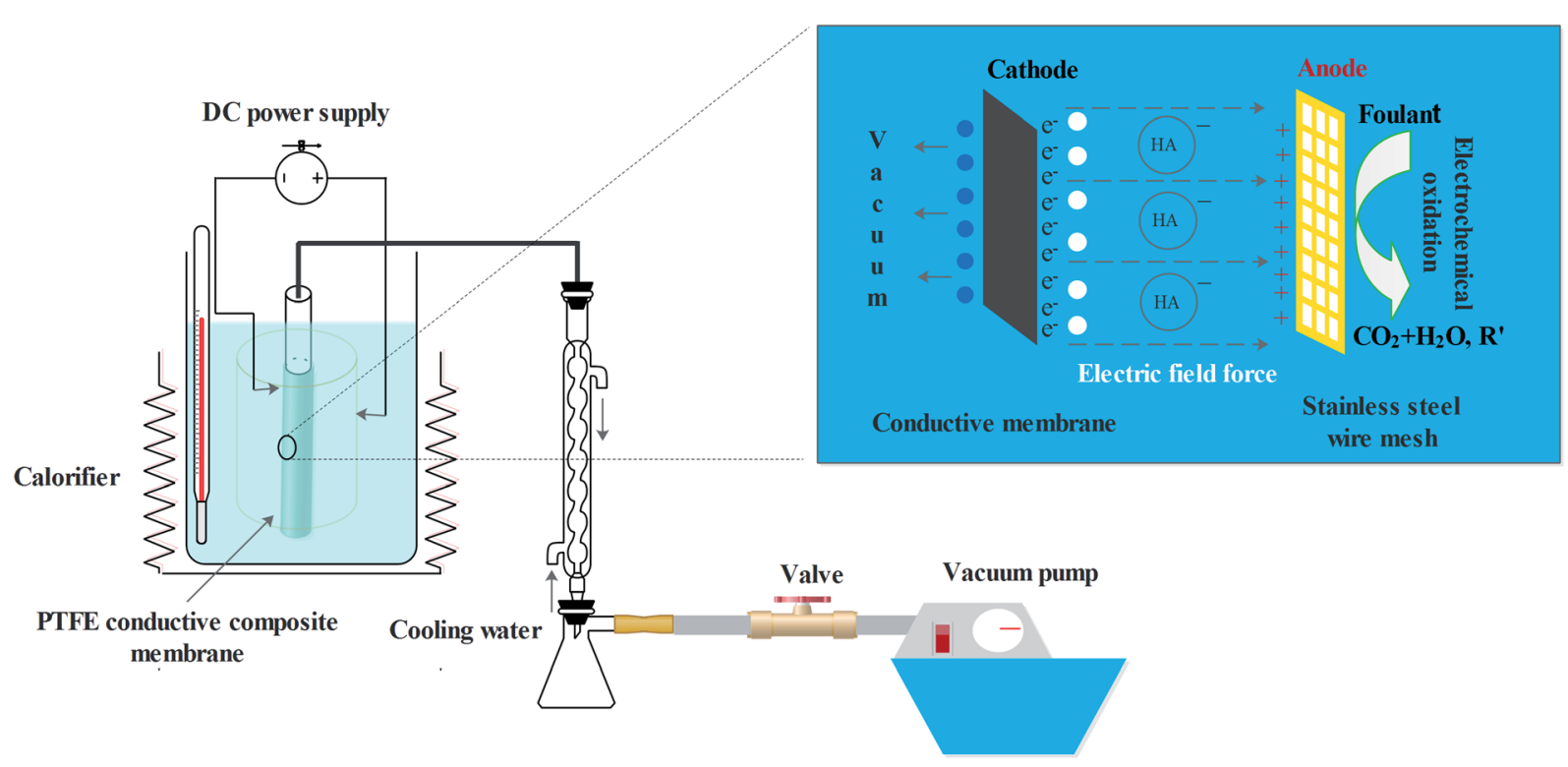

Fig. 2 Schematic of the EVMD process. 


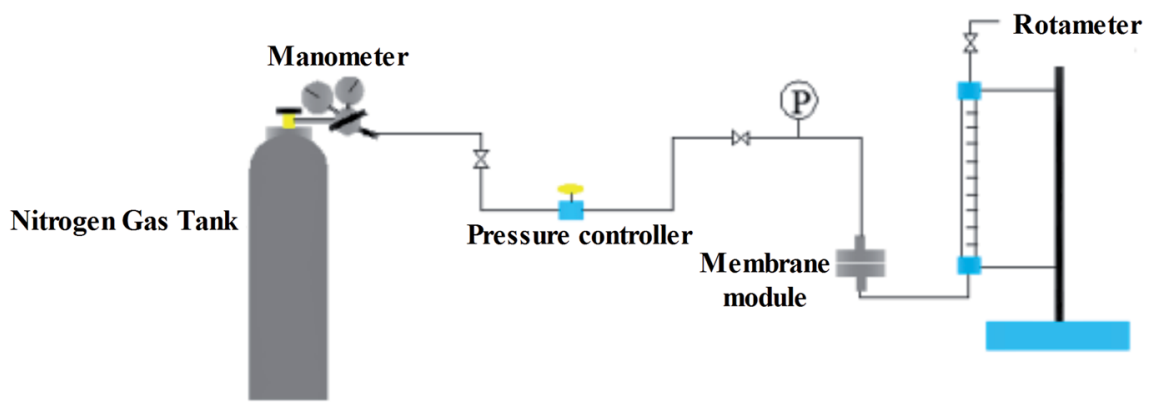

Fig. 3 Schematic of $\mathrm{N}_{2}$ gas flux testing device.

showed in Fig. 1. The membrane was then vacuum dried at $0.09 \mathrm{MPa}$ and $60{ }^{\circ} \mathrm{C}$. The effective area of the prepared membrane was $38.48 \mathrm{~cm}^{2}$.

\subsection{EVMD test}

A prepared PTFE conductive membrane (with an effective surface area of $20 \mathrm{~cm}^{2}$ ) was fixed to a porous tube to create a tubular shaped membrane module. During the EVMD test, an aqueous solution of HA (20 $\left.\mathrm{mg} \mathrm{L}^{-1}\right)$ pretreated with an aqueous solution of $\mathrm{NaOH}\left(40 \mathrm{~g} \mathrm{~L}^{-1}\right)$ was used as the pollutant. Additionally, an aqueous solution of $\mathrm{NaCl}(3.5 \%$ by wt) was used as both an electrolyte and an inorganic contaminant. During the EVMD process, the temperature of the feed liquid was kept constant at $70{ }^{\circ} \mathrm{C}$ and the vacuum pressure was set at $0.095 \mathrm{MPa}$. An intermittent electric field with an interval of $0.5 \mathrm{~h}$ was applied in order to hopefully mitigate membrane fouling (Fig. 2).

\subsection{Characterization}

2.4.1. Morphology. Field emission scanning electron microscopy (FESEM, HItachi-s-4800) was used to characterize the morphologies of the prepared membranes.
2.4.2. Conductivity. The conductivity of the PTFE membrane was measured using a four probe method (KEITHLEY2700, MULTIMETER/DATA ACQUISITION SYSTEM).

2.4.3. Hydrophobicity. The hydrophobicity of the PTFE membrane was characterized by measuring the water contact angles (Jinshengxin Inspection Instrument Co., Ltd., model JYSP-180).

2.4.4. Permeability. The permeability of the membranes was characterized by measuring the rate of $\mathrm{N}_{2}$ gas flux as determined using a laboratory device (Fig. 3) at a driving force of $0.01 \mathrm{MPa}$. The liquid entrance pressures of water (LEPw) at the membrane's surface were determined using a testing device illustrated in Fig. 4.

\subsection{EVMD separation performance}

2.5.1. Membrane flux. The membrane distillation flux was calculated using the following formula:

$$
J=\frac{V}{A \times t}
$$

where $J$ is the VMD flux in $\mathrm{L} \mathrm{m}^{-2} \mathrm{~h}^{-1}, V$ is the sample volume in $\mathrm{L}, A$ is the effective membrane area in $\mathrm{m}^{2}$, and $t$ is the sampling time in $\mathrm{h}$.

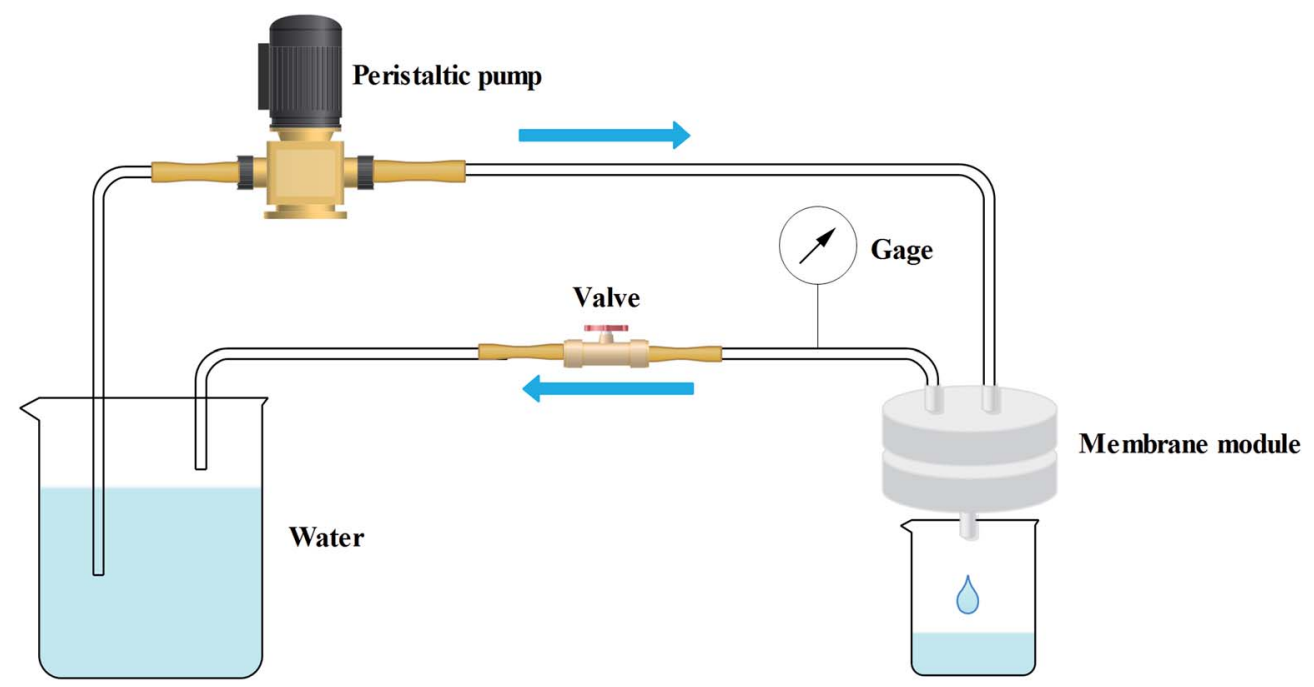

Fig. 4 Schematic of the LEPw testing device. 

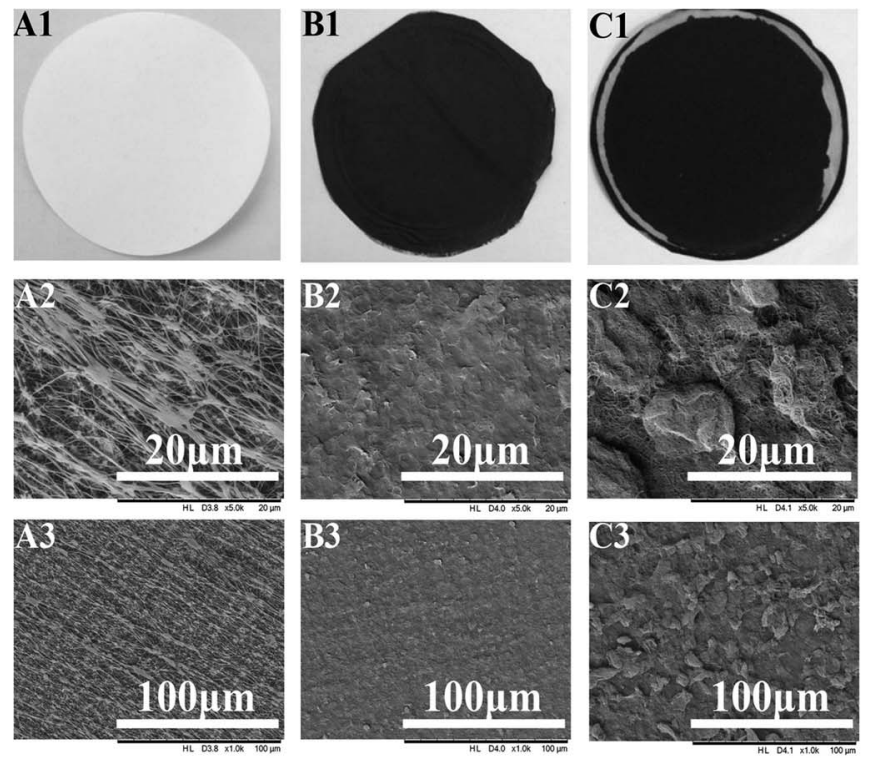
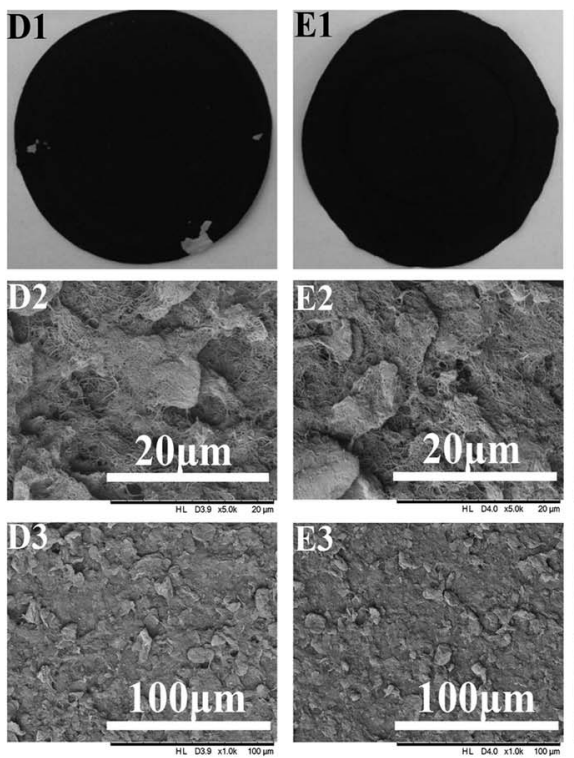
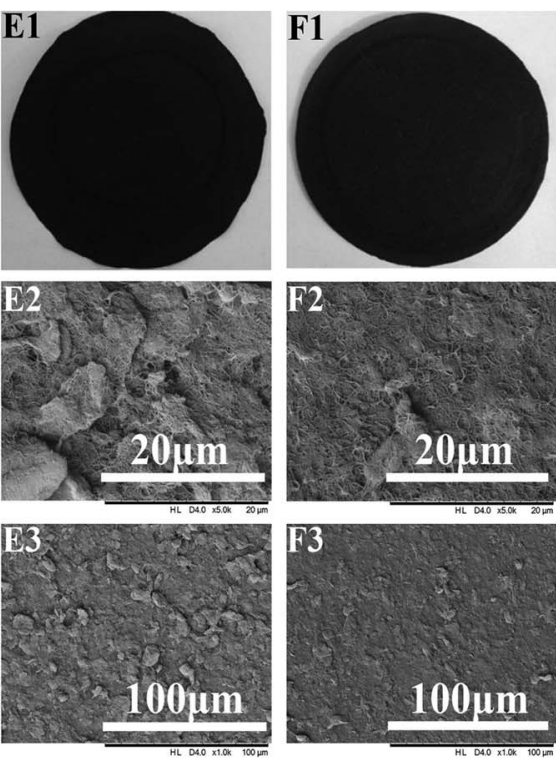

Fig. 5 Digital and SEM images of PTFE conductive membranes with various PUALMs of MWCNTs ((A) raw PTFE membrane; (B) $1 \mathrm{~g}^{-2}$ PUALM; (C) $5 \mathrm{~g} \mathrm{~m}^{-2}$; (D) $10 \mathrm{~g} \mathrm{~m}^{-2}$; (E) $15 \mathrm{~g} \mathrm{~m}^{-2}$; (F) $20 \mathrm{~g} \mathrm{~m}^{-2}$ ).

2.5.2. Rejection. The $\mathrm{NaCl}$ rejection percentage for the VMD process was calculated using the following formula:

$$
R=\left(1-\frac{C_{\mathrm{p}}}{C_{\mathrm{f}}}\right) \times \%
$$

where $R$ is the percent of $\mathrm{NaCl}$ rejection, $C_{\mathrm{f}}$ is the conductivity of the feed solution, and $C_{\mathrm{p}}$ is the conductivity of the permeate water.

\section{Results and discussion}

\subsection{Effects of the PUALM of MWCNTs on membrane performance}

3.1.1. Morphology. As shown in Fig. 5, there are obvious changes to the surface morphology that occurred as a result of MWCNTs being deposited on the membrane surfaces using vacuum filtration. An increase in the PUALM of the MWCNTs on the membrane led to a marked deepening in the membrane

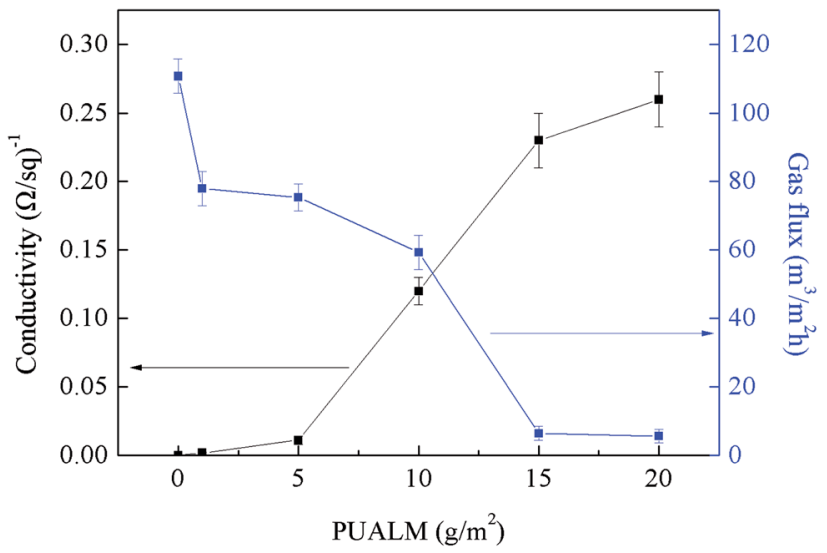

Fig. 6 Changes in membrane gas flux and conductivity for various PUALMS of MWCNTS. color. For a MWCNT PUALM of $5 \mathrm{~g} \mathrm{~m}^{-2}$ or more, a clearly apparent bump structure is visible on the membrane surface, an effect thought to be caused by the superposition of MWCNTs on the membrane surface.

3.1.2. Gas flux and conductivity. A suitable membrane for EVMD requires both good separation performance and excellent conductivity. The reciprocal of square resistance was utilized to characterize the membrane's conductivity. For an increase in the PUALM of the MWCNTs, the conductivity of the PTFE membrane increased, while the gas flux declined significantly (Fig. 6). This decline was due to the deposited MWCNTs on the PTFE membrane blocking many of the membrane pores, as shown in Fig. 5. As the PUALM of the MWCNTs increased from $1 \mathrm{~g} \mathrm{~m}^{-2}$ to $20 \mathrm{~g} \mathrm{~m}^{-2}$, the reciprocal square of the membrane resistance increased from $0.0016 \pm 0.0004$ to $0.26 \pm$

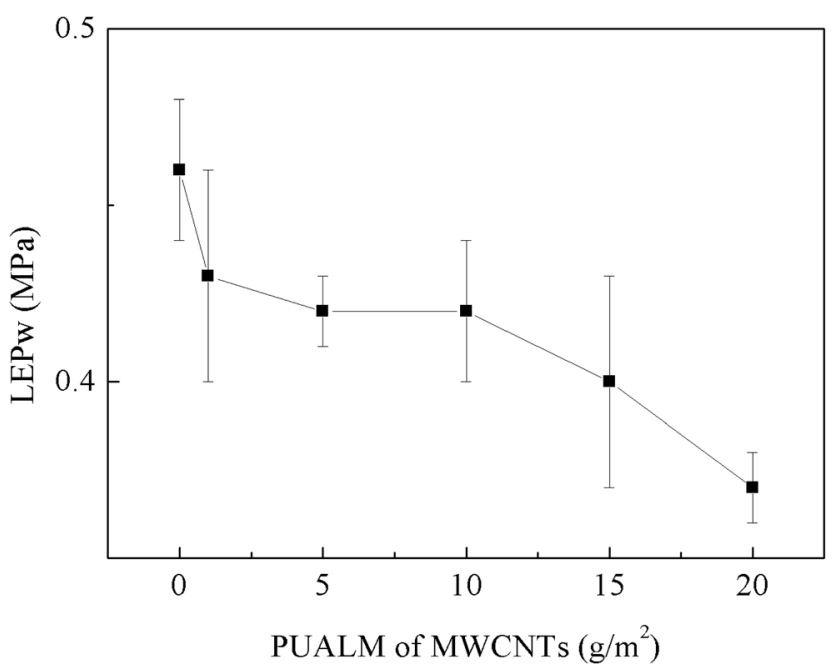

Fig. 7 Effects of the PUALM on the LEPW. 

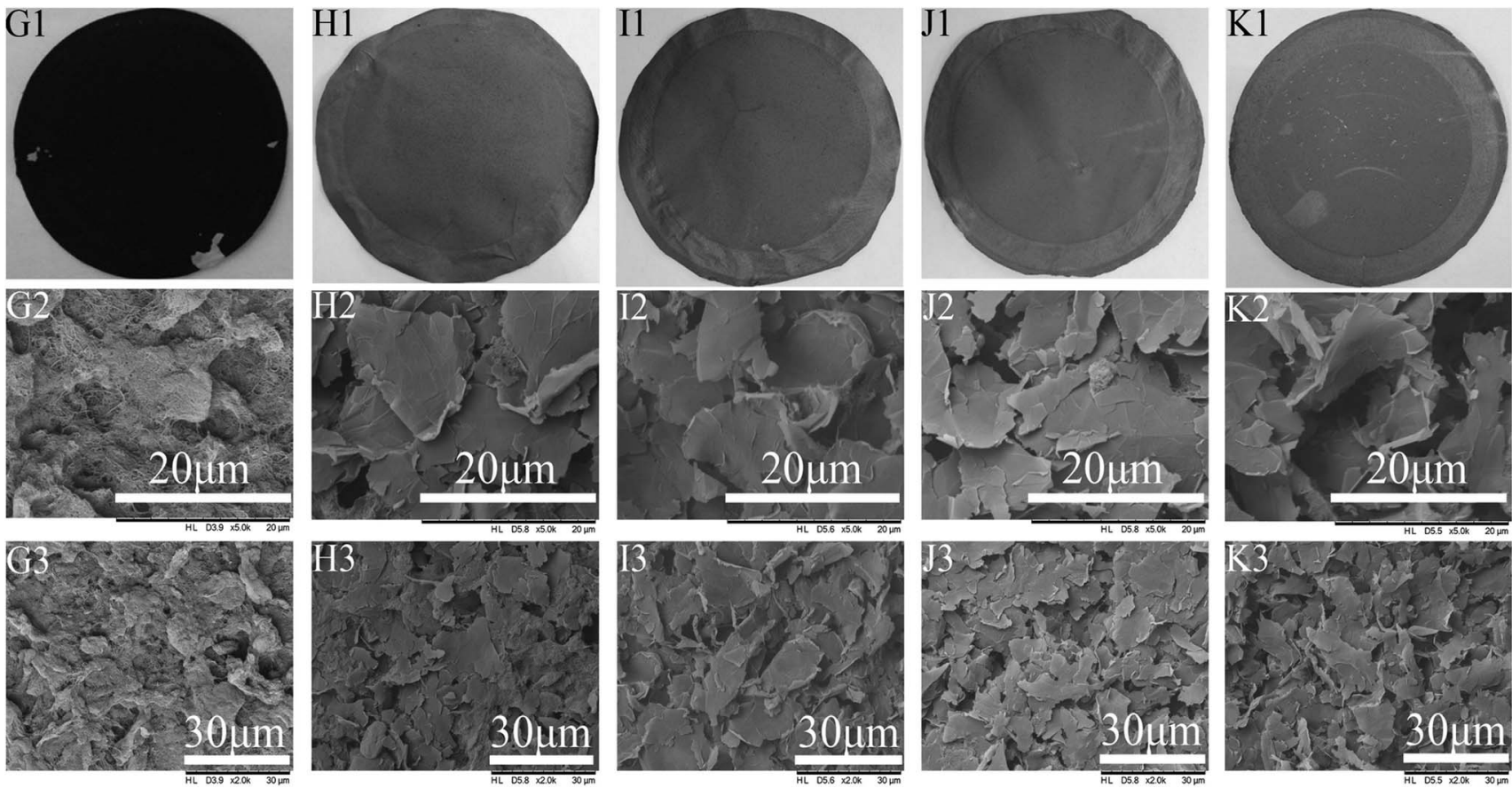

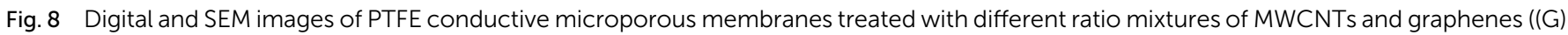
only MWCNTs; (H) $1: 1$; (I) $1: 2$; (J) $1: 3$; (K) $1: 5$ ).

$0.02(\Omega / s q)^{-1}$, showing improved electrical conductivity. This reason was due to the higher PUALM of the MWCNTs diminishing the gaps between MWCNTs which further brought about a lower membrane resistance. Increasing the amount of MWCNTs on the surface lessened the number of gaps between the MWCNT particles and links between MWCNT particles became shorter. This effect alleviated restrictions on electron movement which in turn enhanced membrane conductivity. At a PUALM of $10 \mathrm{~g} \mathrm{~m}^{-2}$ the membranes showed both good conductivity and a high gas flux, as shown in Fig. 6 .

3.1.3. Membrane liquid entrance potential of water (LEPw). LEPw is the minimum pressure required for an aqueous solution to pass through the pores of a dry membrane. Application

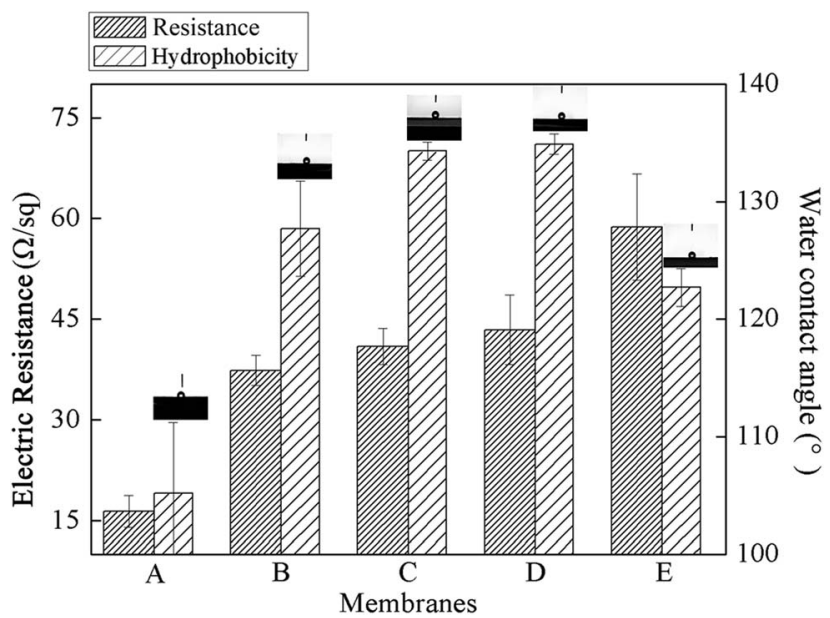

Fig. 9 Effects of mass ratio of graphene to MWCNTs on membranes resistance and hydrophobicity. of a transmembrane hydrostatic pressure that exceeds the LEPw may lead to pore wetting and lower quality for the produced water. In this work, the conductive membrane was also used under VMD conditions, which have higher requirements for the LEPw of the membrane. As can be seen in Fig. 7, due to the carboxylation of the MWCNTs, the LEPw for the membrane dropped slightly with an increase in the PUALM. However, all membranes retained an LEPw value greater than $0.3 \mathrm{MPa}$, a suitable value for VMD.

\subsection{Effects of graphene doped MWCNTs on membrane performance}

Kunli $\mathrm{Goh}^{48}$ had previously reported the formation of a nanostructure on the membrane that improved the membrane

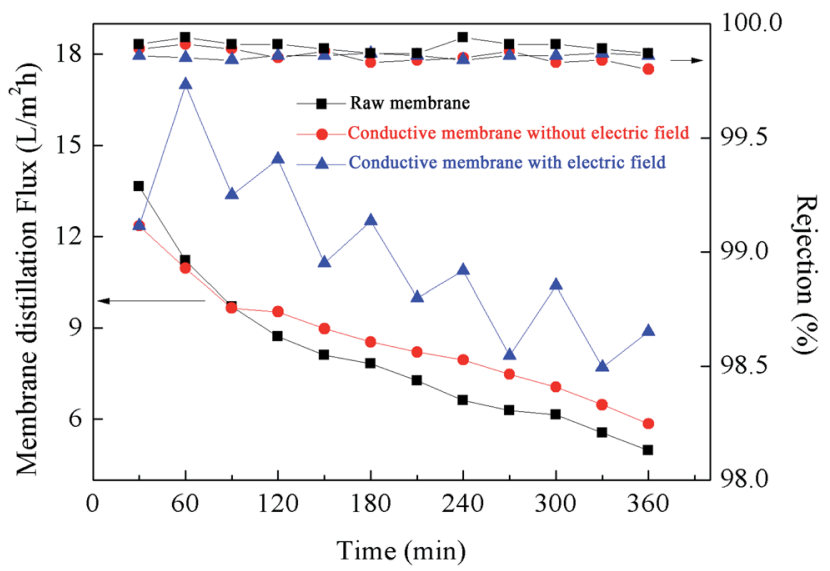

Fig. 10 Membrane distillation flux measured using raw PTFE membranes and conductive microporous PTFE membranes with or without an intermittent electric field at $1.0 \mathrm{~V} \mathrm{~cm}^{-1}$. 
hydrophobicity as well as the distillation flux. In hopes of seeing such benefits and build this nanostructure, a mixture of graphenes and MWCNTs were used as the conductive substrate and the subsequent effects on membrane performance were investigated. The PUALM for all tests was kept at $10 \mathrm{~g} \mathrm{~m}^{-2}$ in order to maintain the good conductivity and separation performance of the membrane.

3.2.1. Morphology. When a mixture of graphenes and MWCNTs was applied as the conductive substrate on the membrane, the graphenes were deposited on the upper surface of the membrane (Fig. 8). As the mass ratio of graphenes in the mixture was increased two effects were observed, first, a larger amount of graphenes were deposited on the membrane surface, and second, the graphene had a more uniform distribution.

3.2.2. Hydrophobicity and conductivity. The hydrophobicity of PTFE membrane was greatly improved by the introduction of graphenes (Fig. 9). For a PUALM of $10 \mathrm{~g} \mathrm{~m}^{-2}$ using only MWCNTs as conductive substrate, the water contact angle was $105.2 \pm 0.6^{\circ}$. However, the water contact angle increased to 134.3 $\pm 0.7^{\circ}$ by the addition of doped graphenes into the MWCNTs at a ratio of $1 / 2$ (graphenes/MWCNTs), showing excellent hydrophobicity. However, comparing with the membrane using only MWCNTs as the conductive substrate, the electric conductivities of membranes using a mixture of graphenes declined which was reflected by the increase of electric resistance. It was owing that, the more air may be trapped between the slice-shape graphenes and rod-shape MWCNTs during the vacuum filtration process, which brought about the enhance of surface electric resistance, and furtherly decreased the membrane's electric conductivity. Overall, for a 1:2 ratio of graphene to MWCNTs showed both good hydrophobicity and conductivity, and they were then applied to EVMD process.

\subsection{Antifouling performance during EVMD}

Use of EVMD was observed to obviously mitigate any decline in membrane distillation flux, indicating effective suppression of membrane fouling. As shown in Fig. 10, all rejection values were measured to be above $99.5 \%$. When raw PTFE membranes were used for VMD, the membrane distillation flux declined sharply to $36.38 \%$ after only 6 hours operation due to serious membrane fouling. It was also observed that membrane fouling resulted from adhesion of HA to the membrane surface and subsequent blocking of membrane pores, as shown in Fig. 11. Compared with a raw PTFE membrane, the rate of decrease for distillation flux across the membrane was slower using the PTFE conductive microporous membrane to conduct VMD without an intermittent electric field, dropping only to $47.37 \%$. Due to the electronegativity of the carboxylated MWCNTs, ${ }^{49}$ it was difficult for HA to adhere to the membrane surface. Also, MWCNTs and graphenes both have excellent thermal conductivities and can act to reduce the temperature polarization and thereby further mitigate the decline in membrane distillation flux. The conductive substrate layer can also act as an antipollution layer. When an intermittent electric field was applied during the VMD process, the membrane distillation flux was unstable, with volatile ups and downs over time. HA is negatively charged and is strongly electronegative, therefore when the PTFE conductive microporous membrane was employed as the cathode, HA in solution was electrically repulsed from the membrane surface and thereby relieved membrane fouling. Furthermore, due to electrochemical oxidation, HA can be degraded near the anode, resulting in a decline of the HA concentration in the feeding liquid during the EVMD process. Another factor for these results may be the generation of $\mathrm{H}_{2} \mathrm{O}_{2}$ in solution which could act to clean the membrane surface at the cathode. The in situ cleaning of the membrane by electrochemically produced $\mathrm{H}_{2} \mathrm{O}_{2}$ has been previously reported to decrease potential membrane fouling. ${ }^{50}$ Furthermore, electrolysis led to the formation of micro-bubbles along the membrane surface, which acted to remove foulants and prevent adsorption of HA onto the membrane surface. ${ }^{34}$
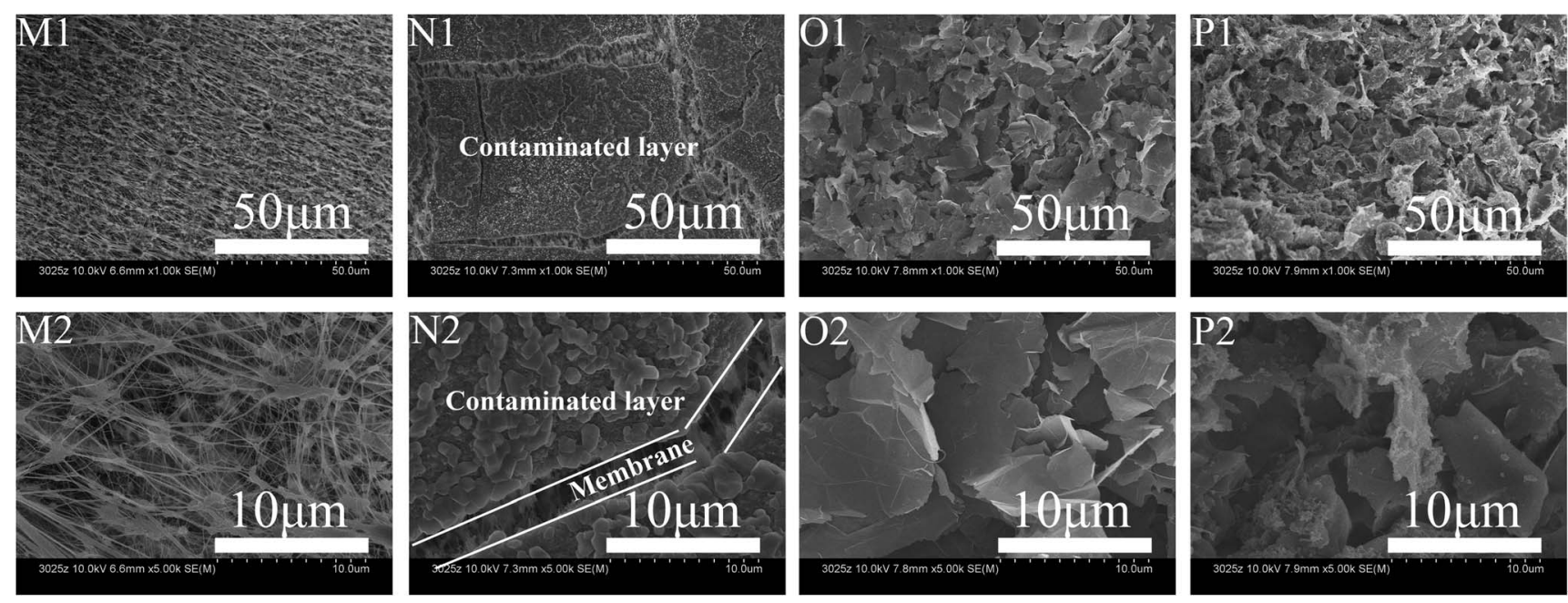

Fig. 11 SEM images of raw PTFE membranes before $(M)$ and after (N) VMD tests as well as PTFE conductive microporous membranes before (O) and after (P) EVMD tests. 
3.3.1. Effects due to the strength of the intermittent electric field. As can be seen in Fig. 12, the antifouling performance of the membrane was highly dependent on the strength of the intermittent electric field. In this work, an intermittent electric field strength of $1.0 \mathrm{~V} \mathrm{~cm}^{-1}$ led to the best antifouling effects for EVMD. Compared with the $1.0 \mathrm{~V} \mathrm{~cm}^{-1}$ electric field strength, the antifouling performance was relatively poor for EVMD using an intermittent electric field strength of $0.5 \mathrm{~V} \mathrm{~cm}^{-1}$ or $1.5 \mathrm{~V} \mathrm{~cm}^{-1}$. Specifically, the membrane distillation flux was $58.38 \%$, $71.98 \%$, and $65.75 \%$ for intermittent electric field strengths of $0.5 \mathrm{~V} \mathrm{~cm}^{-1}, 1.0 \mathrm{~V} \mathrm{~cm}^{-1}$, and $1.5 \mathrm{~V} \mathrm{~cm}^{-1}$, respectively. Two opposing effects can be used to explain this trend. On the one hand, as the intermittent electric field strength decreased, the electric repulsion between HA and the membrane surface also decreased, allowing HA to more easily adhere to the membrane surface. Furthermore, application of a lower strength intermittent electric field led to a reduction of the electrochemical oxidation effect at the anode during EVMD and thus the attraction of HA to the anodic electric field would also be decreased. On the other hand, as the electric field strength becomes too high the HA concentration of feed liquid drops due to the strong electrochemical oxidation at the anode. This produces the desired effect as it reduces adhesion of HA to the membrane surface and mitigates membrane fouling. However, the generation of $\mathrm{H}_{2} \mathrm{O}_{2}$ microbubbles that clean the membrane surface at the cathode is also increased, and could lead to mass transfer resistance resulting from only allowing gas through the membrane pores. Therefore, the choice of the electric field strength was crucial for peak antifouling performance during EVMD. In this work, application of an intermittent electric field with a field strength of $1.0 \mathrm{~V} \mathrm{~cm}^{-1}$ led to the best antifouling action as well as the best membrane distillation flux recovery.

3.3.2. Effects due to HA concentration. As shown in Fig. 13, in the case of VMD using a raw membrane the amount of membrane fouling increased with an increase in the concentration of HA. With each increase in the HA concentration of the feed liquid, the rate of decline for the membrane distillation flux accelerated. Specifically, when HA concentrations were $20 \mathrm{mg} \mathrm{L}^{-1}$, $50 \mathrm{mg} \mathrm{L}^{-1}$, and $100 \mathrm{mg} \mathrm{L}^{-1}$, the membrane distillation flux using the raw membrane decreased to $36.38 \%, 31.84 \%$, and $27.01 \%$,

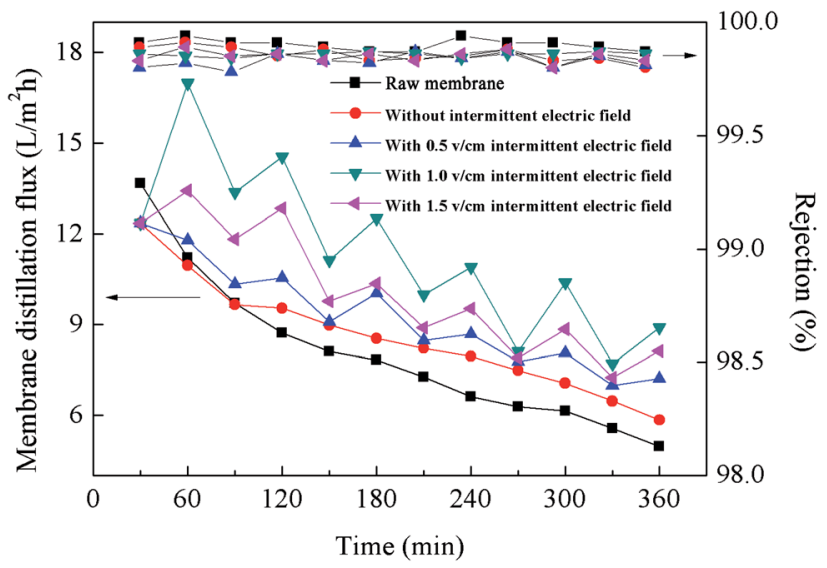

Fig. 12 Membrane distillation flux for various electric field strengths.

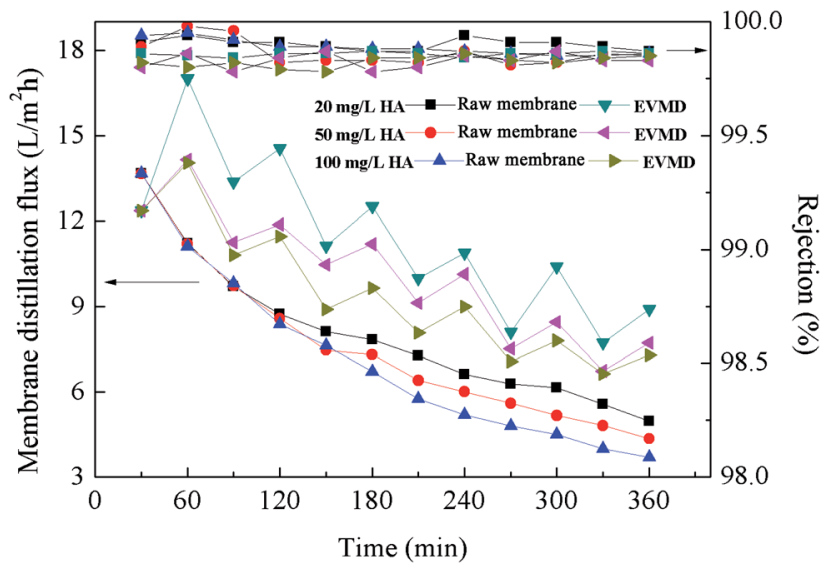

Fig. 13 Membrane distillation flux at different HA concentrations.

respectively. The antifouling performance of EVMD also weakened during increases in HA concentration. Although increasing the HA concentration could act to increase the number of negative charges and thereby both increase the electric repulsion between HA and the PTFE conductive microporous membrane (cathode) and improve electrostatic attraction between the anode and HA, the increase in the probability of HA coming into contact with the membrane and fouling the surface overcame any positive effects due to increased concentration. Furthermore, the HA degradation rate near the anode declined as the HA concentration increased. During the MD process, the mass transfer resistance was seen to increase along with an increase in the feed concentration, while the HA degradation rate near the anode declined. Overall, as HA concentration increased, the membrane distillation flux declined and membrane fouling increased.

\section{Conclusions}

In conclusion, the prepared PTFE conductive microporous membranes possessed excellent conductivity and membranes with a fixed PUALM of $10 \mathrm{~g} \mathrm{~m}^{-2}$. EVMD was observed to effectively mitigate membrane fouling due to electric field and electrochemical action on the pollutants. It was determined that the best antifouling performance and membrane distillation flux recovery rate was achieved using an intermittent electric field with a field strength of $1.0 \mathrm{~V} \mathrm{~cm}^{-1}$. Also, it was observed that the antifouling performance of EVMD was weakened with an increase in HA concentration due to the increased likelihood of HA coming into contact with the membrane surface.

\section{Conflicts of interest}

There are no conflicts to declare.

\section{Acknowledgements}

This work was supported by the Young Elite Scientists Sponsorship Program by China Association for Science and Technology (No. YESS20160168), Tianjin Municipal University Science and Technology Development Fund Project (No. TJ 
20140306), and the Science and Technology Plans of Tianjin (No. 15PTSYJC00240).

\section{References}

1 M. A. Shannon, P. W. Bohn, M. Elimelech, J. G. Georgiadis, B. J. Marinas and A. M. Mayes, Science and technology for water purification in the coming decades, Nature, 2008, 452, 301-310.

$2 \mathrm{M}$. Khayet, Membranes and theoretical modeling of membrane distillation: a review, Adv. Colloid Interface Sci., 2011, 164, 56-88.

3 L. D. Tijing, J.-S. Choi, S. Lee, S.-H. Kim and H. K. Shon, Recent progress of membrane distillation using electrospun nanofibrous membrane, J. Membr. Sci., 2014, 453, 435-462.

4 G. Naidu, S. Jeong, S.-J. Kim, I. S. Kim and S. Vigneswaran, Organic fouling behavior in direct contact membrane distillation, Desalination, 2014, 347, 230-239.

5 L. D. Tijing, Y. C. Woo, J.-S. Choi, S. Lee, S.-H. Kim and H. K. Shon, Fouling and its control in membrane distillation-A review, J. Membr. Sci., 2015, 475, 215-244.

6 E. Drioli, A. Ali and F. Macedonio, Membrane distillation: Recent developments and perspectives, Desalination, 2015, 356, 56-84.

7 F. Shao, C. Hao, L. Ni, Y. Zhang, R. Du, J. Meng, Z. Liu and C. Xiao, Experimental and theoretical research on $\mathrm{N}$ methyl-2-pyrrolidone concentration by vacuum membrane distillation using polypropylene hollow fiber membrane, $J$. Membr. Sci., 2014, 452, 157-164.

8 A. Criscuoli, P. Bafaro and E. Drioli, Vacuum membrane distillation for purifying waters containing arsenic, Desalination, 2013, 323, 17-21.

9 J. Chen, Y. Zhang, Y. Wang, X. Ji, L. Zhang, X. Mi and H. Huang, Removal of inhibitors from lignocellulosic hydrolyzates by vacuum membrane distillation, Bioresour. Technol., 2013, 144, 680-683.

10 X. Lu, Y. Peng, L. Ge, R. Lin, Z. Zhu and S. Liu, Amphiphobic PVDF composite membranes for anti-fouling direct contact membrane distillation, J. Membr. Sci., 2016, 505, 61-69.

11 S. Srisurichan, R. Jiraratananon and A. G. Fane, Humic acid fouling in the membrane distillation process, Desalination, 2005, 174, 63-72.

12 D. Hou, L. Zhang, Z. Wang, H. Fan, J. Wang and H. Huang, Humic acid fouling mitigation by ultrasonic irradiation in membrane distillation process, Sep. Purif. Technol., 2015, 154, 328-337.

13 Y. Z. Tan, J. W. Chew and W. B. Krantz, Effect of humic-acid fouling on membrane distillation, J. Membr. Sci., 2016, 504, 263-273.

14 D. M. Warsinger, J. Swaminathan, E. Guillen-Burrieza, H. A. Arafat and J. H. Lienhard V, Scaling and fouling in membrane distillation for desalination applications: A review, Desalination, 2015, 356, 294-313.

15 A. Kayvani Fard, T. Rhadfi, M. Khraisheh, M. A. Atieh, M. Khraisheh and N. Hilal, Reducing flux decline and fouling of direct contact membrane distillation by utilizing thermal brine from MSF desalination plant, Desalination, 2016, 379, 172-181.

16 A. Zarebska, D. R. Nieto, K. V. Christensen and B. Norddahl, Ammonia recovery from agricultural wastes by membrane distillation: Fouling characterization and mechanism, Water Res., 2014, 56, 1-10.

17 M. Gryta, Fouling in direct contact membrane distillation process, J. Membr. Sci., 2008, 325, 383-394.

18 Z. Ding, L. Liu, Z. Liu and R. Ma, The use of intermittent gas bubbling to control membrane fouling in concentrating TCM extract by membrane distillation, J. Membr. Sci., 2011, 372, 172-181.

$19 \mathrm{~J}$. W. Chew, W. B. Krantz and A. G. Fane, Effect of a macromolecular- or bio-fouling layer on membrane distillation, J. Membr. Sci., 2014, 456, 66-76.

20 Y. Hao, A. Moriya, T. Maruyama, Y. Ohmukai and H. Matsuyama, Effect of metal ions on humic acid fouling of hollow fiber ultrafiltration membrane, J. Membr. Sci., 2011, 376, 247-253.

21 J. I. M. M. Khayet, Effect of salt concentration during the treatment of humic acid solutions by membrane distillation, Desalination, 2004, 168, 9.

22 G. Naidu, S. Jeong and S. Vigneswaran, Interaction of humic substances on fouling in membrane distillation for seawater desalination, Chem. Eng. J., 2015, 262, 946-957.

23 J. R. Du, S. Peldszus, P. M. Huck and X. Feng, Modification of membrane surfaces via microswelling for fouling control in drinking water treatment, J. Membr. Sci., 2015, 475, 488-495.

24 J. Grzechulska-Damszel, S. Mozia and A. W. Morawski, Integration of photocatalysis with membrane processes for purification of water contaminated with organic dyes, Catal. Today, 2010, 156, 295-300.

25 D. Hou, G. Dai, H. Fan, H. Huang and J. Wang, An ultrasonic assisted direct contact membrane distillation hybrid process for desalination, J. Membr. Sci., 2015, 476, 59-67.

26 Y. Yang, J. Li, H. Wang, X. Song, T. Wang, B. He, X. Liang and H. H. Ngo, An Electrocatalytic Membrane Reactor with SelfCleaning Function for Industrial Wastewater Treatment, Angew. Chem., Int. Ed., 2011, 50, 2148-2150.

27 D. Rajkumar and K. Palanivelu, Electrochemical treatment of industrial wastewater, J. Hazard. Mater., 2004, 113, 123129.

28 Y. J. Feng and X. Y. Li, Electro-catalytic oxidation of phenol on several metal-oxide electrodes in aqueous solution, Water Res., 2003, 37, 2399-2407.

29 Y. Q. Wang, B. Gu and W. L. Xu, Electro-catalytic degradation of phenol on several metal-oxide anodes, J. Hazard. Mater., 2009, 162, 1159-1164.

30 L. Liu, F. Zhao, J. Liu and F. Yang, Preparation of highly conductive cathodic membrane with graphene (oxide)/PPy and the membrane antifouling property in filtrating yeast suspensions in EMBR, J. Membr. Sci., 2013, 437, 99-107.

31 J. Huang, Z. Wang, J. Zhang, X. Zhang, J. Ma and Z. Wu, A novel composite conductive microfiltration membrane and its anti-fouling performance with an external electric field in membrane bioreactors,, Sci. Rep., 2015, 5, 9268. 
32 K. Akamatsu, Y. Yoshida, T. Suzaki, Y. Sakai and H. Nagamoto, S.-i. Nakao, Development of a membranecarbon cloth assembly for submerged membrane bioreactors to apply an intermittent electric field for fouling suppression, Sep. Purif. Technol., 2012, 88, 202-207.

33 R. Hashaikeh, B. S. Lalia, V. Kochkodan and N. Hilal, A novel in situ membrane cleaning method using periodic electrolysis, J. Membr. Sci., 2014, 471, 149-154.

34 B. S. Lalia, F. E. Ahmed, T. Shah, N. Hilal and R. Hashaikeh, Electrically conductive membranes based on carbon nanostructures for self-cleaning of biofouling, Desalination, 2015, 360, 8-12.

35 Y. Yang, J. Li, H. Wang, X. Song, T. Wang, B. He, X. Liang and H. H. Ngo, An electrocatalytic membrane reactor with selfcleaning function for industrial wastewater treatment, Angew. Chem., 2011, 50, 2148-2150.

36 X. Huang, Z. Zeng, Z. Fan, J. Liu and H. Zhang, GrapheneBased Electrodes, Adv. Mater., 2012, 24, 5979-6004.

37 N. O. Weiss, H. Zhou, L. Liao, Y. Liu, S. Jiang, Y. Huang and X. Duan, Graphene: An Emerging Electronic Material, Adv. Mater., 2012, 24, 5782-5825.

38 H. Chen, M. B. Müller, K. J. Gilmore, G. G. Wallace and D. Li, Mechanically Strong, Electrically Conductive, and Biocompatible Graphene Paper, Adv. Mater., 2008, 20, 3557-3561.

39 O. C. Compton, D. A. Dikin, K. W. Putz, L. C. Brinson and S. T. Nguyen, Electrically conductive "alkylated" graphene paper via chemical reduction of amine-functionalized graphene oxide paper, Adv. Mater., 2010, 22, 892-896.

40 S. Garaj, W. Hubbard, A. Reina, J. Kong, D. Branton and J. A. Golovchenko, Graphene as a subnanometre transelectrode membrane, Nature, 2010, 467, 190-193.

41 Z. Q. Tian, S. H. Lim, C. K. Poh, Z. Tang, Z. Xia, Z. Luo, P. K. Shen, D. Chua, Y. P. Feng, Z. Shen and J. Lin, A Highly Order-Structured Membrane Electrode Assembly with Vertically Aligned Carbon Nanotubes for Ultra-Low Pt
Loading PEM Fuel Cells,, Adv. Energy Mater., 2011, 1, 12051214.

42 Y. Han, Z. Xu and C. Gao, Ultrathin Graphene Nanofiltration Membrane for Water Purification, Adv. Funct. Mater., 2013, 23, 3693-3700.

43 H. Y. Yang, Z. J. Han, S. F. Yu, K. L. Pey, K. Ostrikov and R. Karnik, Carbon nanotube membranes with ultrahigh specific adsorption capacity for water desalination and purification, Nat. Commun., 2013, 4, 2220.

44 L. Dumée, V. Germain, K. Sears, J. Schütz, N. Finn, M. Duke, S. Cerneaux, D. Cornu and S. Gray, Enhanced durability and hydrophobicity of carbon nanotube bucky paper membranes in membrane distillation, J. Membr. Sci., 2011, 376, 241-246.

45 S. Kar, R. C. Bindal and P. K. Tewari, Carbon nanotube membranes for desalination and water purification: Challenges and opportunities, Nano Today, 2012, 7, 385-389.

46 D. A. Dikin, S. Stankovich, E. J. Zimney, R. D. Piner, G. H. Dommett, G. Evmenenko, S. T. Nguyen and R. S. Ruoff, Preparation and characterization of graphene oxide paper, Nature, 2007, 448, 457-460.

47 A. S. Brady-Estevez, S. Kang and M. Elimelech, A singlewalled-carbon-nanotube filter for removal of viral and bacterial pathogens, Small, 2008, 4, 481-484.

48 W. J. Kunli Goh, H. E. Karahan, S. Zhai, L. Wei, D. Yu, R. Wang, A. G. Fane and Y. Chen, All-Carbon Nanoarchitectures as High-Performance Separation Membranes with Superior Stability, Adv. Funct. Mater., 2015, 25, 12.

49 S.-M. Park, J. Jung, S. Lee, Y. Baek, J. Yoon, D. K. Seo and Y. H. Kim, Fouling and rejection behavior of carbon nanotube membranes, Desalination, 2014, 343, 180-186.

50 Y. K. Wang, W. W. Li, G. P. Sheng, B. J. Shi and H. Q. Yu, Insitu utilization of generated electricity in an electrochemical membrane bioreactor to mitigate membrane fouling, Water Res., 2013, 47, 5794-5800. 